This is an electronic reprint of the original article. This reprint may differ from the original in pagination and typographic detail.

Author(s): Ehrlén, Veera

Title: Communication Practices and Social Tie Formation: A Case Study of Recreational Lifestyle Sports Cultures

Year: $\quad 2017$

Version:

Please cite the original version:

Ehrlén, V. (2017). Communication Practices and Social Tie Formation: A Case Study of Recreational Lifestyle Sports Cultures. International Journal of Sport Communication, 10(3), 393-413. https://doi.org/10.1123/ijsc.2017-0032

All material supplied via JYX is protected by copyright and other intellectual property rights, and duplication or sale of all or part of any of the repository collections is not permitted, except that material may be duplicated by you for your research use or educational purposes in electronic or print form. You must obtain permission for any other use. Electronic or print copies may not be offered, whether for sale or otherwise to anyone who is not an authorised user. 
Communication Practices and Social Tie Formation: A Case

Study of Recreational Lifestyle Sports Cultures

Veera Ehrlén

University of Jyväskylä

Ehrlén is with the Department of Language and Communication Studies, University of Jyväskylä, Finland. Please address author correspondence to Veera Ehrlén at veera.ehrlen@jyu.fi

Accepted author manuscript version reprinted, by permission, from International Journal of Sport Communication, 2017, 10(3): 393-413, https://doi.org/10.1123/ijsc.2017-0032. C 2017 Human Kinetics, Inc. 
Abstract

This case study examines contemporary recreational sports practitioners' communication practices and social tie formation from the perspective of two lifestyle sports disciplines: climbing and trail running. Online survey results from 301 climbers and trail runners from Finland indicate that computer-mediated communication (CMC) has established its place in recreational lifestyle sports cultures; however, it has not done it at the expense of face-to-face $(\mathrm{FtF})$ communication. Online interaction produces weak social ties with instrumental and informative value, but physical location is essential in establishing ties with emotional and appraisal value. This paper argues that it is the sports subculture and individual practitioners' needs that define how interaction is realized, and what importance different online and off-line communication practices have. Besides studying communication practices, this case study explores the social meanings practitioners attribute to their social contacts.

Keywords: computer-mediated communication, social media, social networking, social support, sports practitioners 


\section{Communication Practices and Social Tie Formation: A Case Study of Recreational Lifestyle Sports Cultures}

New communication technologies have changed the dynamics of social interaction (Baym, 2015; Rainie \& Wellman, 2014). In the context of sports, practitioners share online sports-related material such as exercise data; information about events, locations, techniques, and equipment; and stories about success and failure. This process takes place in the form of text, pictures, videos, "likes," and shares on various social media sites. With the help of smartphones, action cameras, activity trackers, and mobile applications, the popularity of sports-related social media practices is growing (Millington, 2014; Thorpe, 2016). However, to a large extent it remains unclear how sports practitioners interact online, what meanings they attribute to their social interaction, and what relevance face-to-face $(\mathrm{FtF})$ communication and joint physical activities still have in recreational sports cultures.

Previous literature shows that social interaction is strongly associated with physical and mental health enhancing outcomes (Berkman, Glass, Brissette, \& Seeman, 2000; Seeman, 1996). Among the documented positive effects of social support are higher perceptions of self-efficacy, improved task performance, better coping, and better disease resistance and recovery (Burleson \& MacGeorge, 2002). Furthermore, studies indicate that by influencing self-efficacy, social peer support subsequently impacts physical activity levels (Anderson, Wojcik, Winett, \& Williams, 2006; Samson \& Solmon, 2011). Recent research has additionally found that sports-related social media use can motivate people to increase their everyday sports practice (Mahan, Seo, Jordan, \& Funk, 2015; Zhang, Brackbill, Yang, \& Centola, 2015). Since physical activity levels among Europeans continue to decrease (European Commission, 2014), further research on the value of social interaction in recreational sports is increasingly important. 
This case study approaches the topic from the perspective of two lifestyle sports disciplines in the Finnish context. The focus of this study is on recreational sports. In this paper, recreational sports practitioners are defined as nonprofessional leisure-time physical activity enthusiasts whose main focus of practice is on physical and mental well-being and on individual development. Recreational sports practitioners engage in a range of exercise levels with varying goals, motivations, and actions. Based on empirical evidence, this study shows that social interaction is an essential part of recreational sports. Moreover, this paper argues that it is the sports subculture and individual practitioners' needs that define how interaction is realized, and what importance different online and off-line communication practices have.

\section{Literature Review}

\section{Online Communication Practices in the Context of Sports}

A contemporary definition of computer-mediated communication (CMC) includes all digitally mediated and, to a growing extent, mobile communication (Herring, 2008). Today, a considerable part of interpersonal interaction is computer mediated and occurs in the form of instant messages, group discussions, and shared activities on social media sites. Following Wenger, Trayner, and de Laat's (2011) conceptual framework, this paper understands social media to include both interest-based online communities, such as YouTube and Reddit, and relationship-based social networking sites, such as Facebook and Twitter.

Previous studies on recreational sports practitioners' CMC practices are few. Most previous research on social media and sports has focused on sports fandom, professional athletes, and sports marketing (see Filo, Lock, \& Karg, 2015). Studies have examined fan-tofan communication (e.g., Boehmer \& Tandoc, 2015; Clavio, 2008; Clavio, Burch, \& Frederick, 2012; Frederick, Clavio, Burch, \& Zimmerman, 2012), athlete-to-athlete communication (e.g., Hambrick, Simmons, Greenhalgh, \& Greenwell, 2010), fan-to-athlete communication (e.g., Clavio \& Kian, 2010; Frederick, Lim, Clavio, \& Walsh, 2012), and 
consumer communication from the perspective of online sites (e.g., Hardin, Koo, Ruihley, Dittmore, \& McGreevey, 2012; Hodge, Pederson, \& Walker, 2015; Kwak, Kim, \& Zimmerman, 2010; Wallace, Wilson, \& Miloch, 2011) and event organization (e.g., Hambrick, 2012).

Hur, Ko, and Valacich (2007) are among the first to study communication practices from the viewpoint of sports practitioners. In their study, Hur et al. focus on practitioners' motivations and concerns with sports-related information retrieval and online shopping. Ojala and Saarela (2010) examine further the needs and motivations of practitioners to share exercise data in multisport online communities. Kang's (2014) research on endurance-sport online communities broadens the perspective from the needs and motivations to other factors that affect members' knowledge-sharing behavior. Most recent studies that investigate the relation between practitioners and online platforms include Geurin-Eagleman's (2015) research on master sports participants' use of online communities, and Stragier, Evens, and Mechant's (2015) research on practitioners' motivations to share physical activity status updates on social networking sites.

The reviewed studies emphasize the relationship between sports practitioners and diverse social media platforms. Most of the conducted research is grounded on a uses and gratifications approach (Katz, Blumler, \& Gurevitch, 1973). Studies have found that information gathering, interaction, experiences, and entertainment are the main gratifications for people to use social media services for sports-related purposes (Geurin-Eagleman, 2015; Hur et al., 2007; Kang, 2014; Ojala \& Saarela, 2010; Stragier et al., 2015). Only two of the reviewed studies additionally suggest forming social contacts or gaining emotional social support (Hur et al., 2007; Ojala \& Saarela, 2010) as a gratification.

Academics have brought up the one-sidedness of the previous research on social media and sports, and therefore they suggest that researchers move toward a more integrated 
application of theory and expand the methodological approaches of future studies (Filo et al., 2015; Pedersen, 2014). In the context of lifestyle sports (Wheaton, 2010), a more comprehensive approach on the role of social media in sports has already been adopted. Many recent studies rely on the conceptual framework that Woermann (2012) builds in his research on social media practices in freeskiing culture. At the heart of Woermann's analysis is the content that practitioners themselves produce and consume online. Woermann argues that recording and sharing sports activities enable practitioners to experience the technical details and the aesthetic nature of the performance, and thus help them develop their sports practice. However, reflection online is by no means an individually conducted activity. On the contrary, Woermann's research shows that sharing on social media is a unifying practice among members of a subculture (Woermann 2012).

Similarly, Jones (2011) and MacKay and Dallaire (2012) study skateboarders, Dumont (2014) climbers, and Olive (2015) surfers with the focus on production and consumption of self-produced material online. Reviewed studies on lifestyle sports strongly agree that the use of social media has been integrated into sports practice. Physical experiences and social media shape each other as practitioners increasingly and continuously share and consume media products (Dumont, 2014; Hutchins, 2011; Jones, 2011; MacKay \& Dallaire, 2012; Olive, 2015; Woermann, 2012). In this process, the line separating producer and consumer is fading. Woermann (2012), following Dumont (2015), describes prosumption, the consumption of self-produced leisure content, as an ongoing process that challenges commercial sports media.

Research on sports practitioners' social interactions helps us understand practices of prosumption, identity formation, power relations, and cultural hierarchies in lifestyle sports cultures (Thorpe, 2016). This study attempts to broaden the scope of previous research mainly focused on proficient lifestyle sports by looking at recreational practitioners' social 
interactions online and FtF. Whereas all of the reviewed studies on lifestyle sports have been conducted with qualitative methods, this study takes a mixed-methods approach with the goal of extending understanding of contemporary lifestyle sports cultures. Furthermore, this paper looks at both communication practices in lifestyle sports and the reasons behind communicating and forming social ties with other practitioners.

\section{Social Ties and Social Support}

Social ties are "the links that bind individuals to other individuals, as manifested in the frequency and kinds of communications among individuals" (Pickering and King, 1995, p. 480). Using their social ties, people share various resources, such as information or goods. Social ties can be either weak or strong. People who are connected through strong ties are often willing to share more resources, compared with people who are connected through weak ties (Wellman \& Wortley, 1990). However, a group of people connected via strong ties are limited to the resources within the group unless some of the members have access to other groups through their weak ties (Burt, 1993). The strength of the weak ties is therefore that they provide more diverse resources than do strong ties (Granovetter, 1973).

When sharing resources, individuals also exchange social support. Social support can be informational, instrumental, appraisal, or emotional (Berkman et al., 2000). In the context of sports, informational support can be seen as providing information about sports gear, instrumental support as teaching sports techniques, appraisal support as encouraging a fellow practitioner to overcome a physical challenge, and emotional support as consoling a practitioner after an unsuccessful attempt.

Social support has been shown to impact physical activity behavior indirectly by influencing self-regulation and self-efficacy (Anderson et al., 2006; Samson \& Solmon, 2011) or intention (Cavallo et al., 2013). Social support can be exchanged between two people or among many people. Network support "enables people to feel part of a group 
whose members have common interests and concerns" (Cutrona \& Russell, 1990, p. 322). Mahan et al.'s (2015) research on social network support indicates that the use of runningrelated social media has an impact on running behavior, and overall life satisfaction. Furthermore, Zhang et al. (2015) conducted a controlled trial on online social networks and physical activity, which shows that adding a social comparison element to a support network increases participants' physical activity levels.

In the present paper, social ties and contacts are used as synonyms, and defined as interpersonal weak or strong connections to other practitioners within the same sport. In this study, both interpersonal and network support are taken into consideration. Instead of measuring the relationship between online activities and sports behavior (as in Mahan et al., 2015; Zhang et al., 2015), this study aims to gain a better understanding of the social motivations that lie behind them. Moreover, to identify which social norms are products of sports subcultures, this study makes comparisons between two sports disciplines.

\section{Purpose of the Study}

This case study examines contemporary recreational sports practitioners' communication practices and social tie formation from the perspective of two sports disciplines: climbing and trail running. The purpose of this paper is to investigate practitioners' social interaction, and the meanings they attribute to it. This study looks at similarities and differences between the selected sports. The comparison is done to find out which factors affect social tie formation and, consequently, social support exchange. The following research questions are posed to meet the goals of the study:

RQ1: What is the role of CMC technologies in the context of recreational lifestyle sports?

RQ2: How and why do recreational lifestyle sports practitioners form social 
COMMUNICATION AND SOCIAL TIES

ties with each other?

RQ3: What are the relationships among practitioners' communication practices, social tie formation, and the meanings attributed to social ties?

\section{Method}

\section{Sample and Procedure}

This study is limited to individual recreational sports practice; in other words, elite sports, team sports, and sports clubs are excluded from the study. Moreover, this research has its focus on physical activities that can be labeled as lifestyle sports (Wheaton, 2010). The central common factor in lifestyle sports is practitioners' holistic orientation toward the practice. In lifestyle sports, participants' physical and mental as well as cultural, emotional, and existential needs are taken account (Atkinson, 2010).

Two lifestyle sports disciplines, climbing and trail running, were selected for the study. A choice was made among lifestyle sports disciplines that have a long tradition of practice, have gained popularity in recent years, are practiced around the globe, and are clearly visible online. To some extent, comparisons between the two sports enable generalization of the results to other lifestyle sports disciplines. Climbers and trail runners were studied in Helsinki, Finland. Helsinki was chosen for this study because both climbing and trail running are practiced widely and have strong communities in the region.

\section{Data Collection and Distribution}

Data collection took place from March to May 2016. The online questionnaire was promoted on sports-specific Facebook groups and online communities, and directed toward practitioners living in the Helsinki area. Permission for promoting the questionnaire was given by the administrators of the sites and specific groups. The questionnaire was available in Finnish and English. Participants were not asked to disclose their nationalities or promised 


\section{COMMUNICATION AND SOCIAL TIES}

any rewards for participation. As the questionnaire was only promoted online, the collected data were limited to people who use social media as a part of their sports practice.

In the questionnaire, participants were asked questions related to their climbing or trail running communication practices and sports-specific social contacts. Social contacts were defined in the questionnaire as "people you know through climbing/ trail running." Most questions were close ended and had multiple choices as well as space for supplementary answers. Different perspectives for examining social interaction were how, where, with whom, and how often it took place. Following, participants were given Likert-scale statements regarding their social contacts in the context of a sports discipline. The used statements measured to what extent practitioners receive informational, instrumental, appraisal, and emotional support from other practitioners. In closing, participants could answer two open-ended questions about the meaningfulness of their social ties related to climbing or trail running.

Altogether, 301 climbers and trail runners answered the questionnaire. Of these participants, $59 \%$ were climbers and $42 \%$ were trail runners. Regarding gender, $53 \%$ were male, $46 \%$ female, and $1 \%$ other. In terms of age, $18 \%$ were in the age group $15-29,49 \%$ in $30-39,27 \%$ in $40-49$, and $6 \%$ in $50-69$. A combined variable of practice length, frequency, and self-estimated competence shows that $16 \%$ of participants can be classified as novice practitioners, $60 \%$ as intermediate practitioners, and $24 \%$ as advanced practitioners.

\section{Data Analysis}

Questionnaire data were analyzed using statistical analysis (SPSS) software. Statistical analysis was used to summarize and describe the empirical data and to investigate relationships among different variables. Descriptive statistics and independent samples $\mathrm{t}$ test were calculated for these purposes. Open-ended questions (256 answers) were coded 
inductively and analyzed using qualitative content analysis. The purpose of the inductive analysis was to identify themes that may not have been taken into account in the questionnaire design. Coding required reading through all the answers three times. Sample responses were selected from each emerging theme. Some of the sample responses were translated from Finnish by the author.

\section{Results}

\section{Face-to-Face Communication}

On average, $90 \%$ of practitioners in both sports interact $\mathrm{FtF}$ with other practitioners (Table 1). However, climbers communicate comparatively more FtF. Almost $60 \%$ of climbers interact at indoor or outdoor sports sites once a week or more, whereas less than $20 \%$ of trail runners do it as often. In comparison, trail runners interact more at sports events. However, because the number of events practitioners participate in yearly is limited, the overall amount of trail runners' FtF communication with other practitioners is considerably lower, compared with that of climbers.

The reason why climbers engage more FtF with each other is likely because climbing is geographically more defined and limited compared with trail running, and thus climbers have a higher probability of meeting other climbers while they practice the sport. Moreover, indoor climbing halls provide a year-around location for climbers to frequently meet and engage FtF. A question about participants' sports practice supports this reasoning. Almost $80 \%$ of trail runners state that they practice alone at times, whereas only slightly over $40 \%$ of climbers ever practice alone. As for trail runners, the lack of well-defined locations may explain the importance of sports events as FtF interaction locales. 
COMMUNICATION AND SOCIAL TIES

\section{Computer-Mediated Communication}

The results show that most practitioners who took part in the questionnaire are active users of social media (Table 2). On average, more than $90 \%$ of practitioners follow and over $70 \%$ take part in sports-related discussion online. Furthermore, more than $90 \%$ of practitioners read and 30\% write sports-related articles, reviews, or blog posts online. The frequency of consuming textual content is significantly higher compared with the frequency of producing it. Most practitioners consume content weekly but produce it only occasionally. Trail runners both consume and produce textual content somewhat more actively, compared with climbers.

Apart from textual content, practitioners frequently consume visual content online. More than $90 \%$ of practitioners watch sports-related pictures and videos online, and most do it on a weekly basis. Climbers consume visual content slightly more often, compared with trail runners. Besides consuming, on average $80 \%$ of practitioners occasionally take sportsrelated photos and/or record sports-related videos.

In addition to consuming and producing textual and visual content, practitioners share it too. Over $60 \%$ of practitioners share sports-related articles, reviews, or blog posts online. Moreover, $70 \%$ of practitioners share photos and videos they have watched, and more than $70 \%$ of practitioners share photos and videos that they have taken themselves. However, the average frequency of all sharing activities is less than once a month.

The only CMC practice that shows a significant difference between the two sports is recording and sharing sports exercise data with the help of technology such as sports watches, activity trackers, or mobile applications. Of trail runners, $90 \%$ record and almost $60 \%$ share exercise data, whereas only over $30 \%$ of climbers record and less than $20 \%$ share data with 
COMMUNICATION AND SOCIAL TIES

other practitioners. Most trail runners record exercise data weekly but share it only occasionally.

A review of mediated communication channels (Table 3) reveals that social networking sites provide the main channels for practitioners to communicate personally with each other. By contrast, online communities and e-mail are not widely used for one-on-one communication. Comparison between the sports shows that trail runners communicate slightly more via online communities than do climbers. Conversely, the results indicate that climbers use more personal communication channels, as they communicate more via phone calls, text messages, and mobile applications. The results thus suggest that climbers form more personal social connections with other practitioners than do trail runners.

\section{Social Ties}

The results presented above show that practitioners have an evident need to interact with each other. As a consequence of interaction, practitioners may form social ties. The results of the questionnaire reveal that most practitioners in both sports form social ties with other practitioners (Table 4). However, the locations where ties are formed vary between the sports. In line with the previous findings, the results show that most climbers form ties at indoor or outdoor sports sites, whereas most trail runners form ties at sports events and online.

Meanings related to social ties. A five-point Likert scale was further used to measure what meanings practitioners attribute to their social ties. Average scale values were counted for each sport, and a t test was used to measure statistical significance between the mean values. Table 5 shows the extent to which practitioners of each sport agree on the statements about their social ties. 
The results of the questionnaire indicate that practitioners attribute many instrumental and informative meanings to their social ties. For practitioners, sports-related contacts provide information about indoor and outdoor sports sites, events, and gear. Moreover, social ties provide sports-related news and entertainment as well as advice on training techniques.

Apart from informational and instrumental support, social ties provide emotional and appraisal support. When it comes to emotional and appraisal support, the results show significant differences between the sports. Climbers more often feel that their social ties are caring and motivating, provide a sense of belonging, and help them develop in their practice. Consequently, climbers find their social ties more important than do trail runners. The reason for this is assumingly because climbers interact more $\mathrm{FtF}$.

To test the assumption of FtF communication being crucial for forming contacts with emotional value, practitioners in both sports were divided into two groups, depending on how often they interact FtF with other practitioners. The previous statements about social contacts were used, and with the help of a t test, the counted means were compared between the practitioners who interact with other practitioners $\mathrm{FtF}$ less than once a week and at least once a week. The results (Table 6) reveal that those practitioners who interact more FtF attribute stronger emotional meanings to their social contacts, and thus, presumably, form stronger social ties with other practitioners. It is however relevant to note that a comparison between practitioners in the similar categories shows that climbers in both categories attribute stronger emotional meanings to their social contacts than do trail runners.

Explanations for the perceived differences between climbing and trail running can be found from the specific and cultural variations between the sports. For example, in climbing, forming contacts is often a necessity because of security reasons. While climbing partners secure each other, they are likely to give technical advice too, and thus help each other to develop in their practice. Moreover, as noted earlier, training conditions in each sport affect 
how and where practitioners interact, and thus what kinds of ties they form with each other. If conditions make interaction difficult during practice, practitioners look for interaction elsewhere. In this regard, social media offer many possibilities for practitioners to get connected.

Reasons for forming social ties. An inductive analysis of all open-ended questions revealed additional meanings and reasons for why practitioners form social ties with other practitioners. Most of these reasons could be found in both trail runners' and climbers' answers. Categorization of the coded data brought out the following six main reasons for forming social ties:

Friendship and family relations. The most frequently coded reason for forming social ties is the fact that practitioners want to form deeper friendships and relationships with other practitioners. For many climbers and trail runners, these relationships extend beyond physical practice. A 29-year-old male said, "I spend time with my climbing friends even when I'm not climbing." Similarly, a 46-year-old female noted: "Some of my trail-running contacts have become friends also outside trail running."

Besides friends, some practitioners have a partner or family members with whom they practice. A 23-year-old female climber stated, "Me and my spouse share climbing as a lifestyle." Other practitioners express a wish for a partner. For example, a 32-year-old female said she would "like to find a like-minded partner among trail runners."

Companionship and community. For many practitioners, other people provide training company. Especially in climbing, forming social ties is related to security. As stated by a 28 -year-old female, "The more climbing partners you have, the better chances you have that you don't need to climb alone without belayers." Trust and security are topics that climbers often mention together. A 34-year-old female said, "I want to practice with people 
whom I can trust.” Also, many trail runners think that training companionship increases security during the practice. A 40-year-old male runner stated, "It's more fun and safer to practice in a group."

Besides providing security, many practitioners think that sports-related social ties provide added motivation for practice. A 56-year-old male runner reflected thus: "They [other runners] make me do harder and longer training sessions that I couldn't complete alone.” Likewise, a 39-year-old female noted: “Other climbers help me challenge myself in climbing without taking unnecessary risks."

For some practitioners, joint practice provides a sense of community. A 37-year old male climbers stated: "We have experienced small and big adventures together. Those are the memories that connect people." Similarly, a 46-year-old female trail runner noted: "It's nice to share experiences and to belong to a group." A 35-year-old female climber contemplated further: "Climbing contacts provide a community that might only be bound by climbing. It's refreshing because in no other context do I have such differing types of friends."

Extended training possibilities. Many practitioners state that forming social contacts considerably extends their own training possibilities. For example, a 34-year-old female said, “Climbing alone wouldn't work with my children, but with climbing friends we have spent many nice days outdoors.” For trail runners, training company often enables running on unknown grounds. A 46-year-old female noted: "I would be fine without social contacts, but the practice would be lonely and limited to the paths that I know."

Some practitioners travel far away to do sports together. A 40-year-old male runner stressed the importance of "organizing and participating in events together, and all kinds of practical things such as sharing travel or accommodation." Likewise, a 28 -year-old nonbinary 
climber said, "We organize climbing trips and get-togethers and share rides to climbing sites."

Sharing. Many practitioners highlight a shared passion, values, or lifestyle as a common ground for forming social ties within a sport. A 29-year-old female reflected thus: "I often realize that I and other trail runners share many similar values such as respect for nature, equality between people, liberalism, etc." Similarly, a 31-year-old female stated: "It's very easy to spend time with other climbers because we share a passion and a lifestyle and enjoy similar things."

In line with the quantitative findings, sharing knowledge and experience emerged as a theme from the qualitative data, and was used as a reason for forming social ties. A 33-yearold nonbinary climber said, "It's nice to exchange beta with other climbers and, for example, information regarding security." Similarly, a 46-year-old female stated: "It's nice to hear about experiences and get advice from other runners." Sharing knowledge is especially appreciated by practitioners at lower levels of competence. A 39-year-old female climber stated: "I want to learn from people who are more experienced than I am."

Social nature of humans. Some practitioners reason that forming social contacts is a part of human nature. A 31-year-old male runner stated: "Relations with other people are important." Similarly, a 36-year-old male climber said: "I think social contacts are important no matter with whom you form them."

Some climbers stress the social nature of the sport. A 29-year-old male said, "I want to form social contacts because climbing is a social sport. Most often you practice climbing together, even when bouldering alone." Similarly, a 40-year-old male explained: "Climbing is above all a social sport. Failure is a big part of the sport and the few moments of success in climbing are worth sharing with someone." 
COMMUNICATION AND SOCIAL TIES

Time used for practice. Some practitioners want to form social ties because they dedicate a considerable amount of their free time to practice. A 28-year old female noted: "Climbing is a time-consuming sport, and that's why there is not much time for other social contacts." Similarly, a 52-year-old male said, "I spend half of my free time on trail-running paths, and so it's natural to form contacts." Practice can also provide time to disengage from everyday life. A 28-year-old female climber put it this way: "Sometimes it's good to have contacts who are completely outside of work and my 'other life.'”

Reasons for not forming social ties. As the quantitative analysis shows, not all practitioners form social ties with each other. Categorization of the coded qualitative data brought out the following three reasons for this:

Lack of interest. The most common reason mentioned was lack of interest. Some practitioners see forming contacts as too much work. A 25-year-old female explained: "Sure it wouldn't be bad to have more contacts, but so far I haven't had the energy to try to find contacts through trail running." Others are satisfied with their existing social network. A 24year-old female climber said, "I have a nice social circle now, so why would I change the surroundings?"

Lack of interest can also be due to a dislike toward other practitioners. A 48-year-old male stated: "Those who have sacrificed their lives for trail running can be very self-centered people." Similarly, a 35-year-old female noted: “There are many friendly climbers, but also nasty ones. Some climbing groups are very clannish. People can be scornful or even try to make climbing harder for others."

Forming contacts is challenging. For some practitioners, forming social ties feels challenging. A 43-year-old female trail runner said, "I'm a lone wolf and it's hard for me to 
take initiative to form social contacts." Similarly, a 33-year-old male climber stated: "I would like to [form social ties], but it feels challenging. I haven't done anything to form contacts."

For some practitioners, a lower level of competence makes forming social ties harder. A 51-year-old female explained: "I haven't been that active in running during the past year, and so I haven't joined any practice, partly because I think I'm too slow." Similarly, a 27year-old female said, "I don't feel like I'm a climber. Therefore, it feels hard to create any contacts with others, and I don't really want to do it either."

Challenges can also arise from lack of time. A 28-year-old male climber noted: "The time reserved for the hobby isn't enough for forming new contacts." Likewise, a 37-year-old male runner stated: "I have other hobbies too, and don't have time to form contacts with everyone."

Practice for individual development. Some practitioners focus solely on their individual development, and thus do not see forming social ties as important. A 32-year-old male climber explained: "I'm more focused on developing myself than on forming social contacts." Similarly, a 24-year old male runner stated: "This hobby is more for myself."

Other practitioners stress the meditative aspects of sports practice. A 42-yearold male runner said, "During practice I want to be by myself, surrounded by my own thoughts—or even better without any thoughts." Likewise, a 34-yearold female stated: "For me, climbing is like meditative yoga or 'a dance on the walls.' I don't practice climbing because of social contacts or to become technically skillful. My goals are different."

\section{Summary of the Results}

The results of this study show that both trail runners and climbers interact actively and in various ways with other practitioners. Through interaction, practitioners form social ties with one another. For the participants in this study, online activities have become a natural 
COMMUNICATION AND SOCIAL TIES

part of sports practice. Practitioners frequently follow sports-related social media content, and occasionally post or share content online. Online communication supports weak ties with instrumental and informative value. High online activity does not however diminish the relevance of FtF communication in contemporary recreational sports. The results show that in the context of sports, location still plays a central role when it comes to establishing social ties with emotional and appraisal value.

Comparisons between the sports indicate that climbers form stronger ties with other practitioners. Climbers communicate more FtF, use more personal mediated communication channels, and attribute more emotional meanings to their social contacts than do trail runners. Explanations for the perceived differences between climbing and trail running can be found from specific and cultural variations between the sports.

A qualitative content analysis reveals that recreational lifestyle sports practitioners form social ties because of a need to develop friendships, family relations, training companionship, and community. They also form social ties to gain extended training possibilities and share life values and experiences with other practitioners. In addition, social ties are formed purely because practitioners spend a considerable amount of time in sports practice. The identified reasons for not forming social contacts are the fact that practitioners do not have interest in it, feel it is challenging, or that they practice sports solely for individual reasons.

\section{Discussion and Implications}

The present paper investigated recreational lifestyle sports practitioners' communication practices and social tie formation. The results of this case study support earlier findings on CMC in lifestyle sports (Dumont, 2014, 2015; Jones, 2011; MacKay \& Dallaire, 2012; Olive, 2015; Woermann, 2012) by showing that for the studied population, 
social media practices have integrated with the physical activity. Practitioners consume, produce, and share information, entertainment, and experiences online. However, this paper argues that even though $\mathrm{CMC}$ has established its place in recreational lifestyle sports cultures, it has not done it at the expense of $\mathrm{FtF}$ communication. Whereas online interaction produces weak social ties with instrumental and informative value, physical location is essential in establishing ties with emotional and appraisal value.

Furthermore, this paper shows that online activities are not limited to proficient lifestyle sports practice but rather reach across the whole sports culture. Recreational practitioners frequently follow sports-related social media content, and occasionally post or share content online. When compared to previous studies on content production and sharing, the quantitative findings of this study indicate that, on a larger scale, these activities may not be as common and frequent as previous qualitative studies (e.g., Jones, 2011; Olive, 2015; Woermann, 2012) on lifestyle sports suggest.

In the present paper, $\mathrm{CMC}$ has been examined as a separate entity from $\mathrm{FtF}$ encounters. The division was made to clarify the role of CMC technologies in recreational lifestyle sports cultures. However, in everyday life, physical activities are often highly mediated, as practitioners record data, photos, and videos while they engage in the sports practice. Online activities should thus be seen as an extension of the physical activities, and vice versa.

Concluding, this paper supports a social shaping approach (Baym, 2015) as a useful perspective for understanding the role of CMC technologies in recreational lifestyle sports. Using this perspective, new communication technologies are seen to provide affordances that guide the actions of practitioners. However, it is the sports culture, situational impacts, and personal choices that shape how practitioners use these technologies. 
The overall comparison between sports disciplines shows that communality and a "doing together" mentality are stronger in the climbing than in the trail running culture. However, a subculture does not define the actions of individual practitioners. As this study shows, some trail runners build stronger supportive contacts with other practitioners, even though the subculture is not necessarily conducive to that. Moreover, both climbers' and trail runners' reasons for forming or not forming social ties within the sport vary between practitioners because they are based on individual needs, goals, and motivations for the practice.

These notions are indications of the power of individualism in contemporary Western societies. In recreational sports, the lack of stable organizational structures gives individual practitioners an authority to decide how and to what extent they want to interact with fellow practitioners, and with whom they want to form social ties. Following this line of argument, this paper suggests that, rather than simply looking at practitioners as members or products of a certain subculture, it may be more prudent to view them as networked individuals (see Rainie \& Wellman, 2014) who rely on the network support provided to them by their sportsrelated social contacts.

Drawing a practical implication, this paper emphasizes the need for sports-related social media platforms and services that awaken individuals' interest for sports and, more importantly, encourage people to practice together. Encouraging recreational sports practitioners to meet $\mathrm{FtF}$ is an initial step in helping them develop stronger influential ties that provide motivation and support to maintain a physically active lifestyle.

\section{Limitations and Future Research}

The most notable limitation concerns the sample of this study. The data used in this study were collected online only, which means that all practitioners who participated in the 
questionnaire use social media as a part of their sports practice. Therefore, those practitioners who do not use social media at all as a part of their practice are outside the scope of this study. The results cannot be generalized to include all sports practitioners in the selected sports. In the future, a comparative study between the users and nonusers of social media would supplement the results of this study.

Furthermore, the sample of this study was limited to one city. Therefore, the results cannot be generalized to nonurban settings or other regions. For future reference, a comparative study conducted in another European city could be used to verify or challenge the conclusions drawn from this study.

As the role of networks in everyday lives of people is growing more important (Rainie \& Wellman, 2014), future research is needed on the network support that recreational sports practitioners provide one another. One future line of research is to look more carefully at what kind of communication and what kind of social support have the best impacts on physical activity levels. Furthermore, research on networked individualism in the context of recreational sports would help deepen the understanding of new organizational structures in contemporary leisure-time cultures.

\section{Case Questions}

1. This case study centered on individual recreational sports. How might the results of this study shift if team sports or professional sports were on focus?

2. This case study was conducted in Finland. Could the results of this study be generalized to other countries?

3. This paper argues that $\mathrm{FtF}$ communication is important for forming strong social ties. What additional values do strong ties give to the sports practice? 
4. Do you agree that social shaping is an appropriate approach for understanding the role of CMC technologies in contemporary lifestyle sports? Why? Why not?

5. Do you think seeing sports practice as a lifestyle affects practitioners' communication practices?

6. Most participants of this study occasionally produce sports-related content online. What do you think motivates practitioners to produce and share content with other practitioners?

7. Why is recording and sharing exercise data such an important part of the trail running but not the climbing subculture?

8. What additional value do social media give to lifestyle sports? What would contemporary lifestyle sports be without social media?

9. This paper argues that sports practitioners ought to be perceived as networked individuals. Does that mean contemporary lifestyle sports communities network based? If yes, how does network-based organization differ from organization in sports clubs?

10. Do you think that the reasons for forming or not forming social ties with other practitioners are true also for practitioners in other lifestyle sports disciplines? 


\section{References}

Anderson, E.S., Wojcik, J.R., Winett, R.A., \& Williams, D.M. (2006). Social-cognitive determinants of physical activity: The influence of social support, self-efficacy, outcome expectations, and self-regulation among participants in a church-based health promotion study. Health Psychology, 25(4), 510-520. doi:10.1037/02786133.25 .4 .510

Atkinson, M. (2010). Entering scapeland: Yoga, fell and post-sport physical cultures. Sport in Society, 13(7-8), 1249-1267. doi:10.1080/17430431003780260

Baym, N.K. (2015). Personal connections in the digital age. Cambridge, UK: Polity Press.

Berkman, L.F., Glass, T., Brissette, I., \& Seeman, T.E. (2000). From social integration to health: Durkheim in the new millennium. Social Science \& Medicine, 51(6), 843857. doi:10.1016/S0277-9536(00)00065-4

Boehmer, J., \& Tandoc, E.C. (2015). Why we retweet: Factors influencing intentions to share sport news on Twitter. International Journal of Sport Communication, 8(2), 212-232. doi:10.1123/ijsc.2015-0011

Burt, R.S. (1993). The social structure of competition. In R. Swedberg (Ed.), Explorations in economic sociology (pp. 65-102). New York: Russell Sage Foundation.

Burleson, B.R., \& MacGeorge, E. (2002). Supportive communication. In M.L. Knapp \& J.A. Daly (Eds.), Handbook of interpersonal communication (3rd ed., pp. 374-422). Thousand Oaks, CA.: Sage Publications.

Cavallo, D.N., Brown, J.D., Tate, D.F., DeVellis, R.F., Zimmer, C., \& Ammerman, A.S. (2013). The role of companionship, esteem, and informational support in explaining physical activity among young women in an online social network intervention. Journal of Behavioral Medicine, 37(5), 955-966. doi:10.1007/s10865-013-9534-5 
COMMUNICATION AND SOCIAL TIES

Clavio, G. (2008). Demographics and usage profiles of users of college sport message boards. International Journal of Sport Communication, 1(4), 434-443. doi:10.1123/ijsc.1.4.434

Clavio, G., \& Kian, T.M. (2010). Uses and gratifications of a retired female athlete's Twitter followers. International Journal of Sport Communication, 3(4), 485-500. doi:10.1123/ ijsc.3.4.485

Clavio, G., Burch, L.M., \& Frederick, E.L. (2012). Networked fandom: Applying systems theory to sport Twitter analysis. International Journal of Sport Communication, 5(4), 522-538. doi:10.1123/ijsc.5.4.522

Cutrona, C.E., \& Russell, D.W. (1990). Type of social support and specific stress: Toward a theory of optimal matching. In B.R. Sarason, I.G. Sarason, \& G. Pierce (Eds.), Social support: An interactional view (pp. 319-366). New York: John Wiley \& Sons.

Dumont, G. (2014). Aesthetics of attachments: Reflexive insights on taste construction in climbing. European Journal of Sport Science, 11(4), 371-387. doi:10.1080/1613817 1.2014 .11687973

Dumont, G. (2015). Co-creation and new media: The entrepreneurial work of climbing photographers in digital times. Anthropology of Work Review, 36(1), 26-36. doi:10.1111/awr.12056

European Commission. (2014). Special Eurobarometer 412: Sport and physical activity. Brussels: Directorate-General for Education and Culture. doi:10.2766/73002

Filo, K., Lock, D., \& Karg, A. (2015). Sport and social media research: A review. Sport Management Review, 18(2), 166-181. doi:10.1016/j.smr.2014.11.001

Frederick, E. L., Clavio, G. E., Burch, L. M., \& Zimmerman, M. H. (2012). Characteristics of users of a mixed- martial-arts Blog: A case study of demographics and usage trends. 
COMMUNICATION AND SOCIAL TIES

International Journal of Sport Communication, 5(1), 109-125.

doi:10.1123/ijsc.5.1.109

Frederick, E.L., Clavio, G.E., Burch, L.M., \& Zimmerman, M.H. (2012). Characteristics of users of a mixed martial arts blog: A case study of demographics and usage trends. International Journal of Sport Communication, 5(1), 109-125. doi:10.1123/ijsc.5.1.109

Frederick, E.L., Lim, C.H., Clavio, G., \& Walsh, P. (2012). Why we follow: An examination of parasocial interaction and fan motivations for following athlete archetypes on Twitter. International Journal of Sport Communication, 5(4), 481-502. doi:10.1123/ijsc.5.4.481

Geurin-Eagleman, A.N. (2015). Online communities among international masters gymnastics participants: A uses and gratifications analysis. International Journal of Sport Communication, 8(3), 313-329. doi:10.1123/IJSC.2015-0045

Granovetter, M.S. (1973). The strength of weak ties. American Journal of Sociology, 78(6), 1360-1380. doi:10.1086/225469

Hambrick, M.E., Simmons, J.M., Greenhalgh, G.P., \& Greenwell, T.C. (2010). Understanding professional athletes' use of Twitter: A content analysis of athlete tweets. International Journal of Sport Communication, 3(4), 454-471. doi:10.1123/ijsc.3.4.454

Hambrick, M.E. (2012). Six degrees of information: Using social network analysis to explore the spread of information within sport social networks. International Journal of Sport Communication, 5(1), 16-34. doi:10.1123/ijsc.5.1.16 
Hardin, R., Koo, G-Y., Ruihley, B., Dittmore, S.W., \& McGreevey, M. (2012). Motivation for consumption of collegiate athletics subscription web sites. International Journal of Sport Communication, 5(3), 368-383. doi:10.1123/ijsc.5.3.368

Herring, S.C. (2008). Foreword. In S. Kelsey \& K. St. Amant (Eds.), Handbook of research on computer mediated communication (pp. xxxv-xxxvi). Boca Raton, FL: Information Science Reference.

Hodge, C., Pederson, J.A., \& Walker, M. (2015). How do you "Like" my style? Examining how communication style influences Facebook behaviors. International Journal of Sport Communication, 8(3), 276-292. doi:10.1123/IJSC.2015-0052

Hur, Y., Ko, Y.J., \& Valacich, J. (2007). Motivation and concerns for online sport consumption. Journal of Sport Management, 21(4), 521-539. doi:10.1123/jsm.21.4.521

Hutchins, B. (2011). The acceleration of media sport culture. Information Communication and Society, 14(2), 237-257. doi:10.1080/1369118X.2010.508534

Jones, R.H. (2011). Sport and re/creation: What skateboarders can teach us about learning. Sport Education and Society, 16(5), 593-611. doi:10.1080/13573322.2011.601139

Kang, B.S. (2014). Factors affecting knowledge-sharing within endurance-sports online communities. Doctoral dissertation. Auckland University of Technology.

Katz, E., Blumler, J.G., \& Gurevitch, M. (1973). Uses and gratifications research. Public Opinion Quarterly, 37(4), 509-523. doi:10.1086/268109

Kwak, D.H., Kim, Y.K., \& Zimmerman, M.H. (2010). User- versus mainstream-media generated content: Media source, message Valence, and team identification and sport consumers' response. International Journal of Sport Communication, 3(4), 402-421. doi:10.1123/ijsc.3.4.402 
COMMUNICATION AND SOCIAL TIES

MacKay, S., \& Dallaire, C. (2012). Skirtboarder net-a-narratives: Young women creating their own skateboarding (re)presentations. International Review for the Sociology of Sport, 48(2), 171-195. doi:10.1177/1012690211432661

Mahan, J.E., Seo, W.J., Jordan, J.S., \& Funk, D. (2015). Exploring the impact of social networking sites on running involvement, running behavior, and social life satisfaction. Sport Management Review, 18(2), 182-192. doi:10.1016/j.smr.2014.02.006

Millington, B. (2014). Smartphone apps and the mobile privatization of health and fitness. Critical Studies in Media Communication, 31(5), 479-493. doi:10.1080/15295036.2014.973429

Ojala, J., \& Saarela, J. (2010). Understanding social needs and motivations to share data in online sports communities. Paper presented at the Proceedings of the 14th International Academic MindTrek Conference: Envisioning Future Media Environments, 95-102. doi:10.1145/1930488.1930508

Olive, R. (2015). Reframing surfing: Physical culture in online spaces. Media International Australia, 155(1), 99-107. doi:10.1177/1329878X1515500112

Pedersen, P.M. (2014). A commentary on social media research from the perspective of a sport communication journal editor. Communication \& Sport, 2(2), 138-142. doi: $10.1177 / 2167479514527428$

Pickering, J.M., \& King, J.L. (1995). Hardwiring weak ties: Interorganizational computermediated communication, occupational communities, and organizational change. Organization Science, 6(4), 479-486. doi:10.1287/orsc.6.4.479

Rainie, L., \& Wellman, B. (2014). Networked: The new social operating system. Cambridge, MA: MIT Press. 
Samson, A., \& Solmon, M. (2011). Examining the sources of self-efficacy for physical activity within the sport and exercise domains. International Review of Sport and Exercise Psychology, 4(1), 70-89. doi:10.1080/1750984X.2011.564643

Seeman, T.E. (1996). Social ties and health: The benefits of social integration. Annals of Epidemiology, 6(5), 442-451. doi:10.1016/S1047-2797(96)00095-6

Stragier, J., Evens, T., \& Mechant, P. (2015). Broadcast yourself: An exploratory study of sharing physical activity on social networking sites. Media International Australia, 155(1), 120-129. doi:10.1177/1329878X1515500114

Thorpe, H. (2016). Action sports, social media, and new technologies: Towards a research agenda. Communication \& Sport. Advanced online publication. doi:10.1177/2167479516638125

Wallace, L., Wilson, J., \& Miloch, K. (2011). Sporting Facebook: A content analysis of NCAA organizational sport pages and big 12 conference athletic department pages. International Journal of Sport Communication, 4(4), 422-444. doi:10.1123/ijsc.4.4.422

Wellman, B., \& Wortley, S. (1990). Different strokes from different folks: Community ties and social support. American Journal of Sociology, 96(3), 558-588. doi:10.1086/229572

Wenger, E., Trayner, B., \& de Laat, M. (2011). Promoting and assessing value creation in communities and networks: A conceptual framework. The Netherlands: Ruud de Moor Centrum.

Wheaton, B. (2010). Introducing the consumption and representation of lifestyle sports. Sport in Society, 13(7-8), 1057-1081. doi:10.1080/17430431003779965 
Woermann, N. (2012). On the slope is on the screen: Prosumption, social media practices, and scopic systems in the freeskiing subculture. The American Behavioral Scientist, 56(4), 618-640. doi:10.1177/0002764211429363

Zhang, J., Brackbill, D., Yang, S., \& Centola, D. (2015). Efficacy and causal mechanism of an online social media intervention to increase physical activity: Results of a randomized controlled trial. Preventive Medicine Reports, 2, 651-657.

doi:10.1016/j.pmedr.2015.08.005 
Appendix

Table 1 Frequency of FtF communication $(\% ; N=301)$

\begin{tabular}{lllllll}
\hline $\begin{array}{l}\text { FtF } \\
\text { communication }\end{array}$ & Practitioners & Never & $\begin{array}{l}\text { Less } \\
\text { than } \\
\text { once a } \\
\text { month }\end{array}$ & $\begin{array}{l}\text { Once or } \\
\text { twice a } \\
\text { month }\end{array}$ & $\begin{array}{l}\text { Once a } \\
\text { week or } \\
\text { more }\end{array}$ & Total \\
\hline $\begin{array}{l}\text { Interact at indoor } \\
\text { or outdoor sites }\end{array}$ & trail runners & 11 & 44 & 29 & 16 & 100 \\
$\begin{array}{l}\text { Interact at sports } \\
\text { events }\end{array}$ & climbers & 2 & 17 & 24 & 56 & 100 \\
& climbers & 32 & 62 & 6 & 0 & 100 \\
\hline
\end{tabular}

Table 2 Frequency of CMC $(\% ; N=301)$

\begin{tabular}{|c|c|c|c|c|c|c|}
\hline CMC activities & Practitioners & Never & $\begin{array}{l}\text { Less } \\
\text { than } \\
\text { once a } \\
\text { month }\end{array}$ & $\begin{array}{l}\text { Once or } \\
\text { twice a } \\
\text { month }\end{array}$ & $\begin{array}{l}\text { Once a } \\
\text { week or } \\
\text { more }\end{array}$ & Total \\
\hline \multirow{2}{*}{$\begin{array}{l}\text { Follow } \\
\text { discussion }\end{array}$} & trail runners & 1 & 6 & 16 & 78 & 100 \\
\hline & climbers & 5 & 10 & 20 & 66 & 100 \\
\hline \multirow{2}{*}{$\begin{array}{l}\text { Participate in } \\
\text { discussion }\end{array}$} & trail runners & 13 & 34 & 30 & 24 & 100 \\
\hline & climbers & 26 & 31 & 16 & 26 & 100 \\
\hline \multirow{2}{*}{$\begin{array}{l}\text { Read articles, } \\
\text { blog posts etc. }\end{array}$} & trail runners & 0 & 16 & 24 & 60 & 100 \\
\hline & climbers & 2 & 17 & 28 & 53 & 100 \\
\hline \multirow{2}{*}{$\begin{array}{l}\text { Write articles, } \\
\text { blog posts etc. }\end{array}$} & trail runners & 58 & 28 & 9 & 5 & 100 \\
\hline & climbers & 80 & 15 & 2 & 2 & 100 \\
\hline \multirow{2}{*}{$\begin{array}{l}\text { Share articles, } \\
\text { blog posts etc. }\end{array}$} & trail runners & 40 & 37 & 15 & 8 & 100 \\
\hline & climbers & 33 & 43 & 13 & 11 & 100 \\
\hline \multirow{3}{*}{$\begin{array}{l}\text { Watch photos or } \\
\text { videos }\end{array}$} & trail runners & 2 & 23 & 30 & 45 & 100 \\
\hline & climbers & 2 & 9 & 29 & 61 & 100 \\
\hline & trail runners & 22 & 31 & 27 & 20 & 100 \\
\hline
\end{tabular}




\begin{tabular}{|c|c|c|c|c|c|c|}
\hline $\begin{array}{l}\text { Take photos or } \\
\text { videos }\end{array}$ & climbers & 7 & 34 & 39 & 19 & 100 \\
\hline \multirow{2}{*}{$\begin{array}{l}\text { Share photos or } \\
\text { videos seen }\end{array}$} & trail runners & 31 & 43 & 18 & 9 & 100 \\
\hline & climbers & 29 & 40 & 22 & 9 & 100 \\
\hline \multirow{2}{*}{$\begin{array}{l}\text { Share photos or } \\
\text { videos taken }\end{array}$} & trail runners & 28 & 40 & 22 & 10 & 100 \\
\hline & climbers & 18 & 44 & 29 & 8 & 100 \\
\hline \multirow{2}{*}{$\begin{array}{l}\text { Record exercise } \\
\text { data }\end{array}$} & trail runners & 10 & 10 & 11 & 69 & 100 \\
\hline & climbers & 63 & 11 & 10 & 17 & 100 \\
\hline \multirow{2}{*}{$\begin{array}{l}\text { Share exercise } \\
\text { data }\end{array}$} & trail runners & 44 & 27 & 9 & 20 & 100 \\
\hline & climbers & 83 & 11 & 2 & 3 & 100 \\
\hline
\end{tabular}

Table 3 The use of mediated communication channels for personal communication (\%; $\mathbf{N}=\mathbf{3 0 1}$ )

\begin{tabular}{lll}
\hline Channel & Trail runners & Climbers \\
\hline Social networking sites & 78 & 84 \\
Online communities & 26 & 3 \\
Phone call & 19 & 47 \\
Video call & 2 & 1 \\
Mobile applications & 30 & 64 \\
SMS & 22 & 46 \\
E-mail & 25 & 20 \\
\hline
\end{tabular}


Table 4 Locations for forming social ties $(\% ; N=301)$

\begin{tabular}{lll}
\hline Location & Trail runners & Climbers \\
\hline Indoor or outdoor sites & 45 & 89 \\
Sports events & 60 & 31 \\
Online & 59 & 42 \\
Elsewhere & 15 & 13 \\
$\begin{array}{l}\text { I do not form social ties with } \\
\text { other practitioners }\end{array}$ & 14 & 5 \\
\hline
\end{tabular}

Table 5 Statements about social contacts

\begin{tabular}{|c|c|c|c|}
\hline Statement & Practitioners & Mean & $S D$ \\
\hline \multirow{2}{*}{$\begin{array}{l}\text { My contacts provide me information } \\
\text { about indoor or outdoor sports sites }\end{array}$} & trail runners & $4.19 *$ & 0.66 \\
\hline & climbers & $4.38 *$ & 0.65 \\
\hline \multirow{2}{*}{$\begin{array}{l}\text { My contacts provide me information } \\
\text { about sports gear }\end{array}$} & trail runners & 4.14 & 0.67 \\
\hline & climbers & 4.24 & 0.65 \\
\hline \multirow{2}{*}{$\begin{array}{l}\text { My contacts provide me information } \\
\text { about sports events }\end{array}$} & trail runners & $4.17^{*}$ & 0.64 \\
\hline & climbers & $3.86^{*}$ & 0.89 \\
\hline \multirow{2}{*}{$\begin{array}{l}\text { My contacts provide me sports-related } \\
\text { news }\end{array}$} & trail runners & 3.82 & 0.70 \\
\hline & climbers & 3.74 & 0.83 \\
\hline \multirow{2}{*}{$\begin{array}{l}\text { My contacts provide me sports-related } \\
\text { entertainment }\end{array}$} & trail runners & 3.98 & 0.64 \\
\hline & climbers & 4.02 & 0.76 \\
\hline \multirow{2}{*}{$\begin{array}{l}\text { My contacts provide me advice on } \\
\text { techniques }\end{array}$} & trail runners & $3.50^{*}$ & 0.78 \\
\hline & climbers & $4.08^{*}$ & 0.78 \\
\hline \multirow{2}{*}{$\begin{array}{l}\text { My contacts provide me a sense of } \\
\text { belonging }\end{array}$} & trail runners & $3.62 *$ & 0.76 \\
\hline & climbers & $4.04 *$ & 0.76 \\
\hline \multirow{2}{*}{ My contacts care about me } & trail runners & $3.26^{*}$ & 0.68 \\
\hline & climbers & $3.88^{*}$ & 0.71 \\
\hline \multirow[t]{2}{*}{ My contacts are important for me } & trail runners & $3.34^{*}$ & 0.71 \\
\hline & climbers & $4.02 *$ & 0.69 \\
\hline \multirow[t]{2}{*}{ My contacts motivate me to practice } & trail runners & $3.62 *$ & 0.97 \\
\hline & climbers & $4.05 *$ & 0.82 \\
\hline \multirow{2}{*}{$\begin{array}{l}\text { I am a better practitioner because of } \\
\text { my contacts }\end{array}$} & trail runners & $3.17^{*}$ & 0.98 \\
\hline & climbers & $4.09^{*}$ & 0.91 \\
\hline
\end{tabular}


Note. Based on a 5-point Likert scale (from strongly disagree to strongly agree).

* indicates statistical significance between trail runners and climbers, $\mathrm{p}<0.05$.

Table 6 Statements about social contacts in relation to FtF communication

\begin{tabular}{llllll}
\hline Statement & Practitioners & $\begin{array}{l}\text { Mean } \\
\text { lessftf }\end{array}$ & SD & $\begin{array}{l}\text { Mean } \\
\text { moreftf }\end{array}$ & SD \\
\hline $\begin{array}{lllll}\text { My contacts provide me a sense of } \\
\text { belonging }\end{array}$ & trail runners & $3.55^{*}$ & 0.78 & $3.90^{*}$ & 0.63 \\
My contacts care about me & climbers & $3.83^{*}$ & 0.81 & $4.21^{*}$ & 0.68 \\
& trail runners & $3.19^{*}$ & 0.66 & $3.62^{*}$ & 0.74 \\
My contacts are important for me & climbers & 3.79 & 0.75 & 3.94 & 0.66 \\
& trail runners & $3.27^{*}$ & 0.69 & $3.62^{*}$ & 0.74 \\
My contacts motivate me to practice & climbers & $3.88^{*}$ & 0.67 & $4.13^{*}$ & 0.68 \\
the sport & climbers & $3.92^{*}$ & 0.73 & $4.17^{*}$ & 0.87 \\
I am a better practitioner because of & trail runners & $2.98^{*}$ & 0.93 & $4.10^{*}$ & 0.63 \\
my contacts & climbers & $3.92^{*}$ & 0.95 & $4.21^{*}$ & 0.87 \\
\hline
\end{tabular}

Note. 5-point Likert scale (from strongly disagree to strongly agree). * indicates statistical significance between practitioners who interact face-to-face less than once a week (lessftf) and at least once a week (moreftf), $\mathrm{p}<0.05$ 